OPINIÃO

OPINION

\title{
Intercambiabilidade entre medicamentos biológicos
}

\author{
Interchangeability of biological medicines
}

Ricardo Garcia'

DOI: 10.21115/JBES.v8.n1.p61-64

Desde que há alguns anos começaram a surgir os medicamentos biossimilares dos biológicos mais complexos, como por exemplo anticorpos monoclonais, muito se tem discutido a respeito de qual seria o impacto da entrada desses medicamentos no mercado. A principal expectativa está relacionada a fatores econômicos, esperando-se uma queda de preços por concorrência, aumentando o acesso da população às terapias biológicas. Por outro lado não se espera benefício clínico por tratar-se de um medicamento similar ao de referência.

Muito se discutiu sobre a necessidade da realização de estudos clínicos para aprovação de um biossimilar. Este tema ainda é discutido amplamente, principalmente no que diz respeito ao tamanho destes estudos. Ainda que uma molécula bem caracterizada, e que tenha comprovado sua qualidade de produção, nos traduza confiança em relação à sua similaridade ao medicamento de referência, são necessários estudos clínicos para comprovar a segurança na utilização destes medicamentos conhecidamente imunogênicos. Essa é uma das muitas incertezas que a comunidade científica ainda tem em relação aos medicamentos biológicos e seus biossimilares.

O que vamos discutir agora com esse texto é a intercambiabilidade entre estes produtos (inovador e biossimilar) e seu potencial impacto na farmacovigilância. Este tema também é alvo de grande angústia e incertezas.

Primeiramente é muito importante contextualizar e conceituar o tema, para que não haja confusão entre intercambiabilidade, switching médico, switching não-médico e substituição automática. A intercambiabilidade é a qualidade que permite o intercâmbio entre um medicamento e outro produto equivalente sem o risco de que um resultado adverso ocorra em consequência deste intercâmbio.

\section{Intercambiabilidade}

A intercambiabilidade é uma prerrogativa regulatória. Deve ser definido pela autoridade reguladora ou de saúde. Tomando como exemplo algumas agências de referência internacional, o FDA (Food and Drug Administration - EUA) define que um medicamento biossimilar pode ser considerado intercambiável se (BPCl, 2010):

- seu resultado clínico esperado for igual àquele produzido por um produtor de referência em qualquer paciente;

- a alternância ou troca repetida entre esses medicamentos não apresente risco adicional à segurança ou redução de eficácia na comparação com o uso continuado do produto de referência.

No caso da agência europeia de medicamentos (EMA), a avaliação não inclui recomendações sobre a possibilidade de utilizar um biossimilar de forma intercambiável com seu medicamento de referência, o dossiê não contém evidências que fundamentem uma deter-

1. CLAPBio - Centro Latino Americano de Pesquisa em Biológicos - UERJ - Universidade do Estado do Rio de Janeiro Contatos: ricardogarcia@clapbio.com - (+55 11) 98114-1515. 
minação sobre a intercambialidade, além de determinar que "para perguntas relacionadas à troca de um medicamento biológico por outro, o paciente deve conversar com seu médico e farmacêutico." A decisão legal sobre a intercambiabilidade cabe aos Estados Membros (EMA, 2012).

A agência regulatória canadense (CADTH - Canadian Agency for Drugs and Technologies in Health) não é a favor da substituição automática, mas permite que a intercambialidade seja determinada por cada província (Health Canada, 2010), na Austrália, de acordo com uma diretriz da TGA (Administração Australiana de Bens Terapêuticos), as bulas de biossimilares devem incluir a seguinte recomendação: "A substituição de [nome do produto de referência] por [nome do produto biossimilar] ou vice-versa deve ocorrer somente sob supervisão do médico" (Therapeutic Goods Administration, 2013).

\section{Switching (alternância) médico}

O switching médico ocorre quando o médico assistente altera a medicação geralmente devido a questões de perda de eficácia, ou de segurança. Por exemplo, o médico assistente muda a terapia do seu paciente que utilizava um medicamento, para outro diferente.

\section{Switching (alternância) não-médico}

A alternância de agentes biológicos em pacientes com adequada e bem tolerada terapia (Rubin et al., 2015; Liu Y et al., 2015). A motivação por trás dessa alternância é geralmente devido a:

- Potencial de redução de custos (Rubin et al.t 2015; Liu Y et al., 2015; Declerck, 2012)

- A preferência do paciente (Van Assche et al., 2012)

- Substituição automática involuntária na dispensação do medicamento

- Pode ocorrer:

- Entre os diferentes agentes da mesma classe terapêutica (Van Assche et al., 2012; Gibofsky et al., 2015)

- De um agente original a seu biossimilar ou vice-versa (CADTH, 2015)

\section{Substituição automática ou involuntária}

Um tema que preocupa de certa forma a comunidade científica, a substituição automática muitas vezes involuntária, ocorre quando um farmacêutico ou o profissional responsável pela dispensação do medicamento substitui um determinado produto prescrito por outro supostamente idêntico. Este tipo de situação é plenamente aceitável quando se trata de medicamentos genéricos. No caso dos medicamentos biológicos e biossimilares, por não se tratarem de medicamentos idênticos, esta prática não é aconselhável, principalmente pela falta de histórico e evidências que nos tragam segurança nesta situação.

\section{Incertezas em relação à intercambiabilidade}

Apesar da definição de intercambiabilidade proposta pelo FDA, não há um consenso quanto ao melhor desenho de estudos clínicos que possa ser usado para confirmar esse conceito. É possível até que o desenho supostamente ideal seja inexequível pelo seu tamanho e custo.

Em 2012, Hans C Ebbers, Michael Muenzberg \& Huub Schellekens realizaram um estudo de revisão de literatura chamado "The safety of switching between therapeutic proteins" ("A segurança na alternância entre proteínas terapêuticas") (Ebbers et al., 2012). Nesta revisão, fornecem uma visão geral de dados relacionados à alternância entre eritropoietina, hormônio de crescimento e (G-CSF) fator estimulador de colônias de granulócitos. O estudo abrange tanto a alternância (switch) entre produtos inovadores dentro da mesma classe quanto a de inovadores para biossimilares e vice-versa.

Os dados sobre a frequência de alternância na prática clínica são escassos, mas os autores não encontraram nenhuma evidência a partir desses limitados dados de ensaios clínicos ou de vigilância pós-comercialização que indicassem que essa alternância de diferentes produtos biofarmacêuticos levasse a preocupações de segurança. É verdade também que a maioria dos estudos revisados não foi desenhada para identificar efeitos adversos relacionados à alternância. Alguns estudos somente acompanharam pacientes depois da alternância num estudo "open label" e de um único braço.

Em outras palavras, essa revisão de literatura é interessante, porém não nos dá robusta evidência que sustente que a intercambiabilidade entre esses produtos, dentro de suas classes terapêuticas, é segura. Além disso, trata-se de medicamentos biológicos bem menos complexos do que anticorpos monoclonais ou proteínas de fusão.

No caso de anticorpos monoclonais, a maioria dos dados de intercambiabilidade está relacionada com anti-TNF (Ebbers et al., 2012):

- Para os pacientes que mudaram por causa de uma falta de eficácia ou intolerância, vários estudos têm demonstrado que a mudança é segura e eficaz (García-Nares et al., 2015 ; Ormerod, 2010).

- Dados clínicos limitados tornam difícil avaliar as consequências clínicas e econômicas da prática de switching não-médico para pacientes com resposta inadequada ao seu tratamento original (Bombardieri et al., 2007; Rubin et al., 2015). 
- Existe evidência muito limitada sobre intercambiabilidade entre produtos inovadores e seus biossimilares, no caso de anticorpos monoclonais (Reynolds, et al., 2012)

Também há incertezas quanto à população que deve ser incluída nesses estudos (BPCl, 2010; Ebbers et al., 2012):

1. Para doenças crônicas, deve-se estudar tanto novos pacientes quanto pacientes estáveis que já receberam tratamento?

2. Estudos sobre a alternância devem ser conduzidos com as populações mais sensíveis?

3. Subpopulações com diferentes perfis de eficácia ou segurança (p.ex., pediátricas)

4. Outros possíveis fatores para consideração:

- Risco de imunogenicidade (frequência, severidade, anticorpos antidrogas)

- Segurança e eficácia em diferentes indicações

- Indicações extrapoladas

É possível extrapolar os próprios dados de intercambiabilidade de uma indicação testada para outra?

No caso de uma indicação aprovada a partir da extrapolação de indicações, é possível determinar corretamente a intercambiabilidade ("acúmulo de incertezas")?

Em 2015 a agência regulatória canadense (CADTH) decidiu realizar um trabalho de revisão de dados sobre a eficácia clínica da intercambiabilidade entre infliximabe inovador e seu biossimilar, comparado ao uso continuado do medicamento inovador. No entanto encontrou evidência muito limitada, o que fez com que avaliasse 3 abstracts apresentados em diferentes conferências, também com limitado número de pacientes estudados. Não houve, nestes abstracts, comparação com o uso continuado de infliximabe inovador. No final, chegaram às seguintes conclusões (CADTH, 2015):

- Os pequenos tamanhos de amostra e a natureza "open label" dos três abstracts limitam as conclusões que podem ser extraídas em relação à eficácia, segurança e imunogenicidade de alternar do infliximabe inovador para o biossimilar.

- A evidência existente não tratou adequadamente preocupações com relação à alternância entre o infliximabe inovador e biossimilar em termos de eficácia continuada, desenvolvimento e impacto de anticorpos anti-droga ao longo do tempo.

\section{Impacto na farmacovigilância}

A vigilância pós-comercialização de uma nova e complexa classe emergente de anticorpos biossimilares é crítica (Vermeer et al., 2015).

A substituição pode comprometer a eficácia da farmacovigilância:
- Se os médicos não estiverem informados, sua capacidade de atribuir eventos adversos ao agente apropriado pode ser prejudicada (Dorner T. et al., 2012)

- Se a reação adversa tiver início tardio: algumas reações adversas - incluindo reações imunogênicas - podem se desenvolver somente após vários meses de tratamento (Gershon et al., 2002)

Outras situações podem ser bem desafiantes:

- O médico que atende o paciente portador de um efeito adverso, pode não ser o médico que prescreveu o medicamento biológico (Vermeer et al., 2015)

- A caixa do remédio pode ter sido descartada pelo paciente (Vermeer et al., 2015)

- Falta de clareza ou acurácia por parte do paciente na hora de reportar o efeito adverso (Vermeer et al., 2015)

A adoção de uma nomenclatura distinguível para cada medicamento biológico, como um "sobrenome" poderia facilitar o monitoramento e a rastreabilidade do produto e do paciente, no caso de haver efeitos adversos.

O FDA publicou em agosto de 2015 seu guia específico para nomenclatura de medicamentos, sugerindo que seja adicionado um sufixo de 4 letras ao nome do Ingrediente Farmacêutico Ativo (IFA) de cada medicamento aprovado (FDA, 2015). Um exemplo é o Filgrastim produzido pela empresa Sandoz ${ }^{T M}$ que, ao ser aprovada em março de 2015, recebeu o nome de Filgrastim- snd $^{\mathrm{TM}}{ }^{\text {. }}$.

Na mesma linha de raciocínio, a Organização Mundial de Saúde propôs a criação de um "Qualificador Biológico" para diferenciar os medicamentos biológicos inovadores dos seus biossimilares (WHO, 2015). Também é uma proposta de um código de quatro letras:

O código consiste em quatro letras, sendo que cada código emitido será atribuído aleatoriamente. As letras serão escolhidas para facilitar a transliteração para vários idiomas e evitar o uso de palavras inadequadas ou que carreguem algum significado

Exemplo: segundo a proposta, a solução para um medicamento biológico como a epoetina alfa seria o uso de nomes como "epoetina alfa bbbb" e "epoetina alfa cccc"

Acreditamos que a adoção de nomes comuns distinguíveis para os medicamentos biológicos podem tornar a notificação de efeitos adversos mais eficaz (Zuñiga, 2010; Casadevall, 2013), otimizando a farmacovigilância e aumentando a precisão dos relatórios desses efeitos adversos e das possíveis ações corretivas (Fitzhugh, 2014; Gaffney, 2012).

\section{Conclusões}

Os medicamentos biossimilares de anticorpos monoclonais têm um histórico de utilização ainda muito limitado, o que dificulta uma boa avaliação pós-comercialização pelo pouco tempo de mercado. 
Até o momento não existem evidências robustas de que, no caso dos anticorpos monoclonais, a intercambiabilidade entre produtos biológicos e seus biossimilares acarretará problemas clínicos relevantes. No entanto, tampouco temos evidências que suportem essa intercambiabilidade, principalmente se levarmos em consideração que a alternância poderá ser não apenas entre o medicamento inovador e um biossimilar, mas entre o inovador e todos os seus biossimilares aprovados e disponíveis no mercado. Por isso tratamos o tema com muito cuidado e precaução, uma vez que em teoria é real a possibilidade de surgirem no médio e longo prazos reações relacionadas à imunogenicidade, como a criação de anticorpos anti-droga, principalmente quando se tratar de pacientes com tratamento em curso e com resultado satisfatório. Nesse caso a alternância poderia representar um risco indesejado.

Acreditamos que a intercambiabilidade será uma prática comum no Brasil, principalmente se levarmos em conta que o maior comprador é o setor público e suas compras são realizadas na modalidade licitatória. Sendo assim, defendemos que ações sejam realizadas para minimizar as consequências dessa situação, como revisões no processo licitatório e um controle rigoroso na dispensação dos medicamentos e na rastreabilidade de efeitos adversos, com a adoção de identificação individualizada.

Faz-se imprescindível a adoção, por parte das empresas farmacêuticas envolvidas, de programas de gestão e minimização de riscos, promovendo dentre outras coisas educação de profissionais de saúde e pacientes, com a devida auditoria da autoridade regulatória.

\section{Referências bibliográficas:}

Biological Qualifier An INN Proposal, Programme on International Nonproprietary Names (INN), Final October 2015, WHO - World Health Organization.

Bombardieri S et al., Rheumatology 2007;46;1191-1199.

$\mathrm{BPCl}$ Act. Biologics Price Competition and Innovation Act of 2009. Federal Register 2010; H.R. 3590-686-702.
CADTH - Canadian Agency for Drugs and Technologies in Health. Rapid Response Report, February 2015, https://www.cadth.ca.

CADTH. Rapid Response Report, February 2015, https://www.cadth.ca.

Casadevall N et al., Expert Opin Biol Ther. 2013 Jul;13(7):1039-47.

Declerck, Paul J. Generics and Biosimilars Initiative Journal (GaBl Journal). 2012;1(1):13-6.

Dorner T. et al. Ann Rheum Dis 2012; 00:1-7;

Ebbers et al. Expert Opin Biol Ther 2012;12:1473-85.

EMA Questions and answers on biosimilar medicines, 27 de setembro de 2012. EMA/837805/2011.

Fitzhugh Burrill Report Generics and Biosimilars BIO argues Fevereiro de 2014.

Gaffney Pharmacovigilance Concerns lead group to call for unique names Regulatory Focus 2012. http://www.raps.org/focus-online/news/ news-article-view/article/2258.

García-Nares, H., Leyva-Carmona, M. I., Pérez-Xochipa, N. and Chiquete, E. (2015), Hypersensitivity reaction to a biosimilar insulin glargine. Journal of Diabetes, 7: 155-157.

Gershon, S. K., Luksenburg, H., Coté, T., Braun, M. M., Sokol, L., Prchal, J. T., ... Bunn, H. F. (2002). Pure red-cell aplasia and recombinant erythropoietin [1] (multiple letters). New England Journal of Medicine, 346(20), 1584-1586.

Gibofsky et al. AMCP 2015, San Diego, Poster.

Health Canada Interchangeability and Substitutability of Subsequent Entry Biologics, Julho de 2010.

Hutchinson D, Tier J, Soper S, Wilson G, Davis M; The conversion of infliximab to adalimumab in stable RA patients. Rheumatology. 2005;44(Suppl. 1):i72.

Liu Y et al. ISPOR 2015, Philadelphia, PHS26

Nonproprietary Naming of Biological Products Guidance for Industry August 2015 Labeling.

Ormerod., A. D. (2010), Switching biologics for psoriasis. British Journal of Dermatology, 163: 667-669.

Reynolds A, et al. Expert Rev Prmacoecon Outcomes Res 2012;12(3):319-333

Rubin et al. ECCO 2015, Barcelona, P354.

TGA Biosimilar Guidance; 30 de julho de 2013.

Van Assche et al. Gut 2012;61:229-34.

Vermeer et al. Expert Opin Drug Saf 2015;14:63-72.

Zuñiga, L. and Calvo, B. (2010), Biosimilars: pharmacovigilance and risk management. Pharmacoepidem. Drug Safe., 19: 661-669. 